\title{
Perancangan Strategi Digital Marketings Dengan Metode Race Pada Layanan Online Food Delivery Berdasarkan Perilaku Pelanggan Generasi $\mathbf{Z}$
}

\author{
Althov Zhorif Naufal ${ }^{1}$, Sri Hariani Eko Wulandari ${ }^{2}$, Ayouvi Poerna Wardhanie ${ }^{3 *}$ \\ Program Studi/ Jurusan Sistem Informasi, Universitas Dinamika \\ Email: 16410100146@dinamika.ac.id, yani@dinamika.ac.id, ayouvi@dinamika.ac.id*
}

\begin{abstract}
Abstrak: Praktik e-business baru yaitu OFD (Online Food Delivery) banyak diminati masyarakat karena membuat proses pemesanan makanan menjadi lebih hemat biaya dan efektif, karena makanan tiba tepat saat dibutuhkan. Oleh karena itu, penelitian ini dilakukan untuk merancang strategi pemasaran digital RACE (Reach, Act, Convert, Engage) berbasis perilaku pelanggan dengan studi kasus pada pengguna layanan OFD di Surabaya. Tahapan digital marketing RACE terbagi menjadi 4 tahapan yaitu Reach, Act, Convert and Engage, sedangkan customer behavior memiliki 10 elemen yang dapat digunakan untuk mengukur perilaku customer yaitu motivasi, gaya hidup, persepsi konsumen, pembelajaran, sikap, komunikasi, kelompok rujukan, keluarga, kelas sosial, dan budaya. Dalam penelitian ini Go-Food dan GrabFood digunakan sebagai objek penelitian karena saat ini sebagai pemimpin segmen OFD untuk kawasan Asia Tenggara termasuk Indonesia. Pengambilan sampel menggunakan teknik Simple Random Sampling dengan total sebanyak 100 responden pengguna Grabfood dan Go-food di Surabaya dan teknik yang digunakan untuk menganalisis data adalah SEM (Structural Equation Modeling). Hasil penelitian menunjukkan bahwa tahap Reach dipengaruhi oleh keluarga sebesar 2,557; tahap Act dipengaruhi oleh komunikasi sebesar 4,657, persepsi konsumen sebesar 3,615, dan sikap sebesar 2,336; tahap Convert dipengaruhi oleh kelompok rujukan sebesar 2,094 dan motivasi sebesat 2,44; tahap Engage dipengaruhi oleh budaya sebesar 2,445, gaya hidup sebesar 3,359, kelompok rujukan sebesar 3.78, keluarga sebesar 4,128, kepribadian sebesar 2,902, komunikasi sebesar 3,87, pembelajaran sebesar 6,167, persepsi konsumen sebesar 4,676, sikap sebesar 3,625.
\end{abstract}

Kata Kunci: E-business, Strategi Pemasaran Digital, Perilaku Konsumen, Online Food Delivery, Metode RACE.

\begin{abstract}
This research aims to design a RACE digital marketing strategy based on customer behavior with a case study on OFD Go-Food and GrabFood service users in Surabaya. The digital marketing RACE stages are divided into four stages, Reach, Act, Convert and Engage. At the same time, customer behavior has ten elements that can measure customer behavior, namely motivation, lifestyle, consumer perception, learning, attitude, communication, referral group, family, social class, and culture. In this study, Go-Food and GrabFood are used as research objects because they are currently the leaders of the OFD segment for the Southeast Asia region, including Indonesia. Sampling using Simple Random Sampling technique with 100 respondents and the method used to analyze the data is SEM (Structural Equation Modeling). The results show that the Reach stage was influenced by the family of 2,557, the Act stage was influenced by three factors such as communication, consumer perception, and attitude with T-statistic 4,657, 3,615, 2,336 respectively, while the Convert stage was influenced by reference group and motivation with T-statistic 2,094 and 2,44, lastly, the Engage stage was influenced by nine factors, culture $(2,445)$, life style $(3,359)$, reference group $(3,78)$, family $(4,128)$, personality $(2,902)$, communication $(3,87)$, learning $(6,167)$, consumer perception $(4,676)$ and attitude $(3,625)$.
\end{abstract}

Keywords: E-business, Digital Marketing Strategy, Customer Behavior, Online Food Delivery, RACE Method 


\section{PENDAHULUAN}

Online Food Delivery (OFD) adalah salah satu model e-business yang memanfaatkan teknologi internet pada telepon pintar untuk melakukan pemesanan makanan, Berdasarkan data yang dihimpun menyebutkan bahwa dalam beberapa dekade terahir tingkat pencarian OFD pada Google meningkat sebanyak 15 kali lipat dalam jangka waktu 4 tahun saja. Hal ini menunjukan bahwa masyarakat yang dahulu hanya menggunakan OFD untuk keadaan mendesak, sekarang sudah menjadi bagian dari kehidupan masyarakat seharihari. Pada laporannya Google juga menyebutkan bahwa untuk wilayah Asia Tenggara pemimpin segmen OFD pada saat ini masih dipegang oleh Go-Food dan GrabFood [1].

Layanan ini menggantikan pesan antar makanan konvensional yang hanya berasal dari tempat makan tertentu dan tidak semua tempat makan memiliki layanan ini serta memungkinkan pengguna memesan makanan di tempat makan favoritnya dan pihak penyedia layanan akan mengantarkan makanan kepada pengguna. Selain kemudahan tersebut, tingginya penetrasi internet di kota-kota besar,serta daya beli masyarakat yang semakin membaik membuat layanan OFD semakin banyak diminati.Para pemain pada bisnis OFD terus bermunculan, baik lokal maupun asing. Layanan yang diberikan juga beragam, Ada yang memberikan layanan pengantaran makanan, jasa catering makanan, hingga pengiriman barang-barang groceries [2]. Terdapat 604 startup yang tercipta mulai tahun 2013-2018, tetapi sayangnya tidak semua startup tersebut mampu meraih kesuksesan. Kesuksesan GrabFood dan Go-Food di bidang OFD menimbulkan pertanyaan, strategi digital marketing bagaimana yang dilakukan agar bisa diterima dan dicintai penggunanya [3]. Oleh sebab itu, penelitian ini adalah berfokus pada upaya untuk mempelajari perilaku pengguna Grabfood dan Go-Food sebagai Online Food Delivery terbesar di Indonesia.

Dalam memahami sebuah produk agar bisa diterima dan dicintai penggunanya maupun pelanggan, maka perlu mengetahui perilaku pengguna produk atau jasa digital. perilaku pelanggan adalah bagaimana proses suatu individu maupun kelompok dalam memilih, menggunakan, dan menilai suatu produk atau jasa berdasarkan apa yang ia rasakan. Perilaku pelanggan ini terbagi menjadi 10 variabel yang terdiri dari motivasi, gaya hidup, persepsi konsumen, pembelajaran, sikap, komunikasi, kelompok rujukan, keluarga, kelas sosial, dan yang terakhir budaya. Disetiap variabel terdapat beberapa sub yang memiliki tujuan untuk menjangkau dan lebih melibatkan pelanggan dalam memenuhi tujuan bisnis [4].

Selain mengetahui perilaku pengguna sehingga bisa mengetahui kriteria produk yang diterima oleh pelanggan, Startup baru juga membutuhkan strategi untuk memasarkan produk atau jasa yang akan mereka berikan. Anggaran keuangan yang terbatas membuat startup memilih strategi digital agar bisa mempromosikan produk/jasa lebih murah dan lebih efektif. Berdasarkan penelitian [5] yang berjudul
"Strategi Pemasaran Online UMKM Makanan" dengan menggunakan strategi digital marketing penyedia layanan dapat melakukan promosi produk mereka secara cepat dengan biaya yang tidak begitu tinggi dan dapat meningkatkan pendapatan sebesar 10-37\%.

Berdasarkan latar belakang diatas, hipotesa dalam penelitian ini adalah bagaimana perilaku pelanggan generasi $\mathrm{Z}$ mempengaruhi perancangan strategi digital marketing pada startup online food delivery. Hasil dari penelitian ini merupakan dokumen perancangan strategi digital marketing yang dapat berguna bagi para founder startup dalam melakukan pemasaran digital, dan memperhitungkan batasanbatasan bagi startup yang baru saja mereka rilis terutama dikalangan generasi $\mathrm{Z}$.

\section{METODE PENELITIAN}

Metode yang digunakan dalam merancang strategi digital marketing pada penelitian ini menggunakan metode RACE dan untuk analisis data menggunakan metode Structural Equation Modeling (SEM).

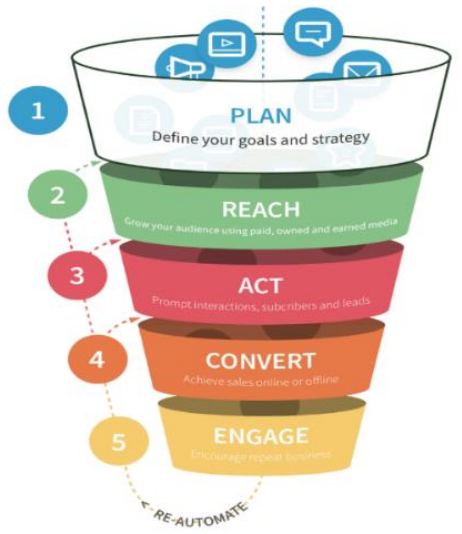

Gambar 1. Metode RACE

Metode RACE merupakan metode digital marketing yang diciptakan oleh Dr Dave Chaffey dengan tujuan untuk membantu para perusahaan yang baru berkembang dalam merencanakan dan mengelola strategi digital dengan cara yang lebih terstruktur. RACE Planning System terdiri dari 4 tahapan antara lain: REACH adalah tahap bagaimana membangun kesadaran merk, produk, dan layanan, $A C T$ adalah tahap bagaimana kita dapat berinteraksi dengan pelanggan, CONVERT adalah tahap bagaimana merubah pelanggan dari interaksi menjadi sebuah pembelian/penggunaan layanan, dan $E N G A G E$ adalah tahap bagaimana menjaga hubungan dengan pelanggan agar terciptanya loyalitas pelanggan [9].

Metode Structural Equation Modeling (SEM) menggunakan program alat bantu perhitungan berupa aplikasi yang bernama SMART-PLS. Pengujian menggunakan SMART-PLS ini terbagi menjadi 3 (tiga) tahapan utama yaitu Estimasi Model PLS-SEM, Evaluasi Outer Model, dan Evaluasi Inner Model. Berikut merupakan tahapan dalam penelitian ini: 


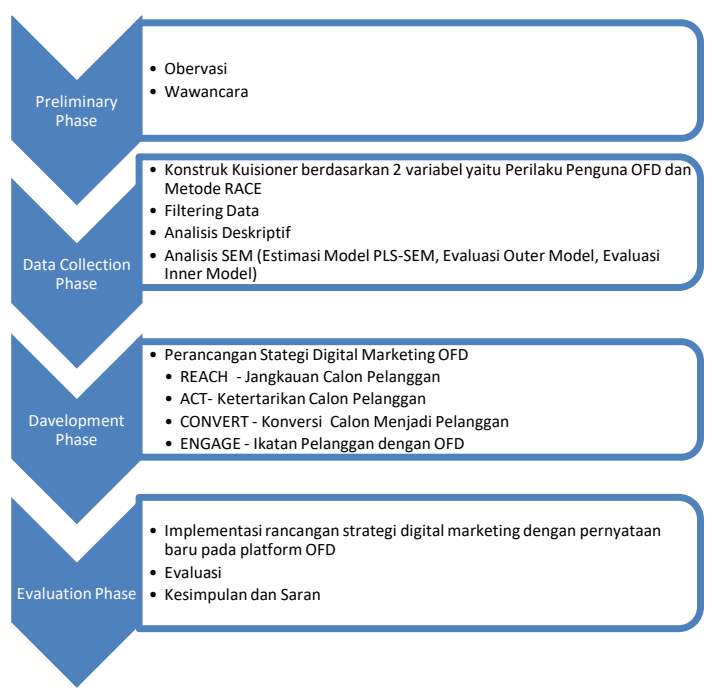

Gambar 2. Tahapan Penelitian

\section{HASIL DAN PEMBAHASAN}

\section{Preliminary Phase}

Hasil dari observasi secara digital dan wawancara terhadap alon startup OFD maupun pengguna OFD yang dilakukan pada tahap preliminary phase menghasilkan kesimpulan bahwa Online Food Delivery memiliki banyak keuntungan bagi pengusaha karena bisa mendapatkan sumberdaya melalui crowd/internet. Permasalahan yang dimiliki oleh pengusaha baru adalah bagaimana menggunakan strategi digital marketing untuk masuk ke pasar(1).

\section{Data Collection Phase}

Dalam menentukan objek pada penelitian ini didasarkan pada perilaku pelanggan terhadap jasa layanan pesan antar makanan [10]. Output yang akan digunakan dalam penelitian yaitu layanan OFD Go-Food dan GrabFood pada pengguna yang berlokasi di Surabaya. Pada tahap pengumpulan data terdapat 2 (dua) tahapan yang akan dibahas, tahapan tersebut terdiri dari penyebaran kuisioner dan tabulasi data. Penyebaran kuisioner dilakukan secara online menggunakan Google Form kepada para pengguna aplikasi Online Food Delivery Go-Food dan GrabFood yang berusia 15-25 tahun (Generasi Z) sebanyak 100 responden yang terdiri atas $44 \%$ Laki-laki dan $56 \%$ perempuan dengan karakteristik sebagai berikut:

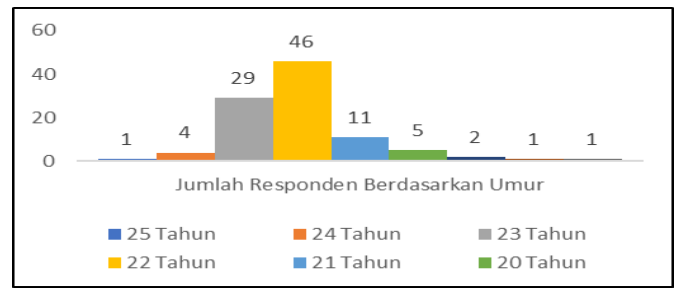

Gambar 3. Jumlah Responden

Berdasarkan hasil survey dapat disimpulkan bahwa sebagian besar pengguna Online Food Delivery (OFD) Grabfood \& Go-Food memiliki jenis kelamin perempuan, hal ini dikarenakan jenis kelamin perempuan memiliki sifat yang lebih komsumtif dibandingkan dengan laki-laki, sehingga bagi para pelaku Online Food Delivery sebaiknya dalam. merancang strategi digital marketing dapat lebih meng-influence para perempuan yang memiliki rentan usia 21 tahun sampai dengan 23 tahun.

Setelah mengetahui karakteristik responden, selanjutnya terdapat dua variabel yang digunakan didalam penelitian ini, yaitu variabel bebas dan variabel terikat. Variabel Bebas didalam penelitian didefinisikan sebagai variabel X (Karakteristik Digital Marketing pada OFD) sedangkan variabel terikat didefinisikan sebagai variabel Y (Perilaku Pelanggan), Berikut merupakan daftar variabel yang digunakan oleh peneliti:

\begin{tabular}{|c|ll|}
\hline Variabel Bebas & \multicolumn{1}{|c|}{ Indikator } \\
\hline Karakteristik Digital Marketing (X) & a. & REACH (X1) \\
& b. ACT (X2) \\
& c. CONVERT (X3) \\
& d. ENGAGE (X4) \\
\hline Variabel Terikat & \multicolumn{1}{c|}{ Indikator } \\
\hline Perilaku Pelanggan (Y) & a. Budaya (Y1) \\
& b. Gaya Hidup (Y2) \\
& c. Kelompok Rujukan (Y3) \\
& d. Keluarga (Y4) \\
& e. Kepribadian (Y5) \\
& f. Komunikasi (Y6) \\
& g. Motivasi (Y7) \\
& h. Pembelajaran (Y8) \\
& i. Persepsi Konsumen (Y9) \\
& j. & Sikap (Y10) \\
\hline
\end{tabular}

Gambar 4. Variabel Penelitian

\section{Development Phase}

Dalam merancang strategi digital marketing tahap awal adalah melakukan benchmark atau studi perilaku pengguna Online Food Delivery Grab Food dan GoFood. Oleh sebab itu, dilakukan Uji Análisis Deskriptif Variabel terhadap Variabel X dan Variabel Y. Berdasarkan estimasi model SEM untuk kedua variable baik karakteristik digital marketing $(\mathrm{x})$ maupun perilaku pelanggan(y) yang telah dilakukan calculate menggunakan SMARTPLS 3 dapat dilihat bahwa sebagian besar nilai indikator sudah berada diatas batas minimum yaitu 0,7. Dapat diartikan bahwa nilai indikator telah valid dan reliabel karena dipahami oleh responden. Pengujian dengan SMART-PLS terbagi menjadi 3 tahapan utama yaitu Estimasi Model PLSSEM, Evaluasi Outer Model, dan Evaluasi Inner Model. Hasil Uji 3 tahap ini dapat dilihat pada gambar 5.

Selanjutnya Tahap Pencarian Variabel Perilaku Pengguna berdasarkan Strategi yang mempengaruhi keputusan untuk memilih Online Food Delivery yang disusun berdasarkan tahapan Strategi Digital Marketing REACH, ACT, COVERT dan ENGAGE. Sebuah variabel dikatakan siginifikan mempengaruhi apabila memiliki nilai T-Statistic > 1,96 dan nilai P-Values berada pada nilai < 0,05. Apabila kedua syarat terpenuhi maka variabel tersebut dikatakan Berpengaruh ("B"), sedangkan apabila hanya salah satu syarat terpenuhi atau tidak terdapat syarat yang terpenuhi maka variabel tersebut dikatakan Tidak Berpengaruh ("TB"). Berikut ini hasil Uji Pengaruh antar Variabel 


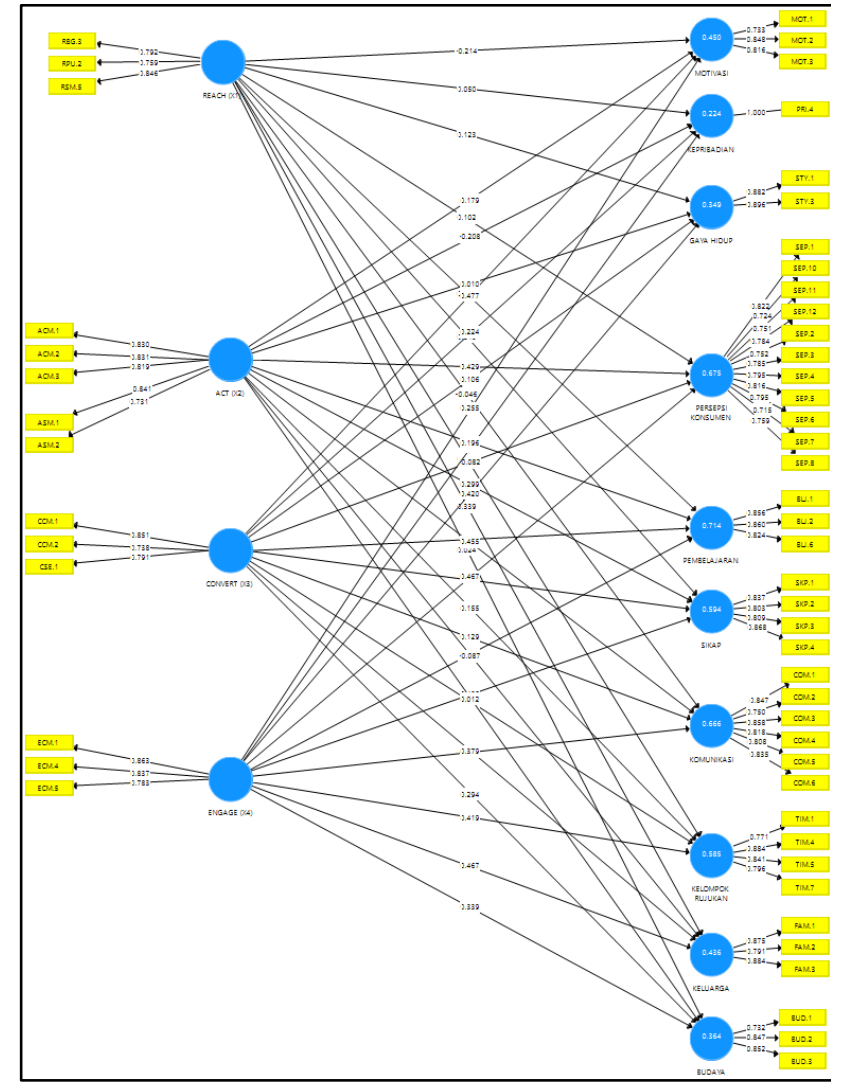

Gambar 5. Hasil Uji Variabel Penelitian

\section{REACH}

Pada penyusunan Strategi Untuk menjangkau pelanggan sebanyak mungkin $(R E A C H)$, variabel perilaku pengguna OFD Grabfood dan Go-Food yang berpengaruh karena memenuhi kedua syarat yaitu PValue $<0.005$ dan Tstatistic $>1.96$ adalah Variabel Keluarga yaitu P-Values $=0,011$ dan nilai T-Statistic sebesar 2,557. Sedangan variabel yang lain tidak terlalu mempengaruhi.

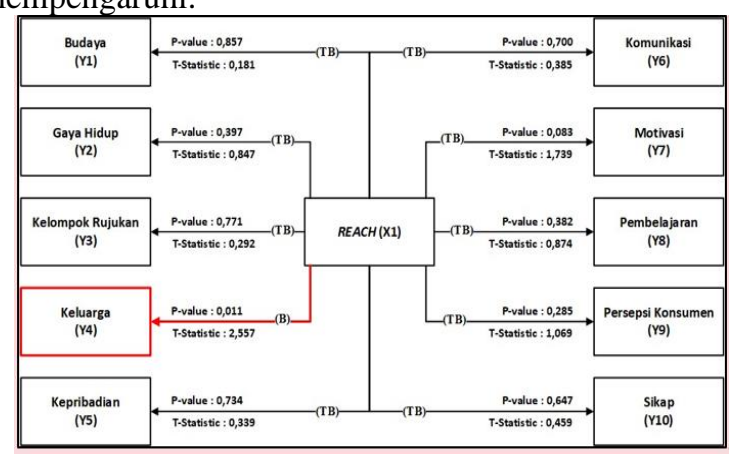

Gambar 6. Hasil Uji Pengaruh antar variabel Perilaku Pengguna pada tahap REACH

\section{ACT}

Pada tahap penyusunan Strategi Untuk membuat pelanggan ingin tahu lebih banyak (ACT), variabel perilaku pengguna OFD Grabfood dan Go-Food yang berpengaruh karena memenuhi syarat adalah Variabel Komunikasi dengan

Pvalue $=0 \mid$ TStatistic $=4.657$, Persepsi konsumen dengan Pvalue $=0 \mid$ TStatistic $=3.615$, dan Sikap dengan Pvalue $=0.02 \mid$ TStatistic $=2.336$.

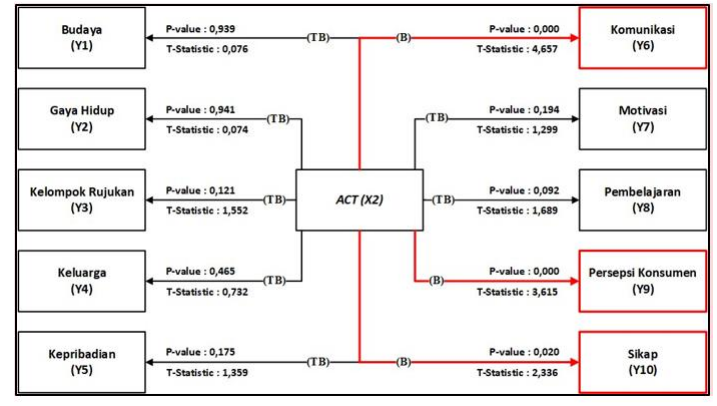

Gambar 7. Hasil Uji Pengaruh antar variabel Perilaku Pengguna pada tahap $A C T$

\section{CONVERT}

Pada tahap penyusunan Strategi Untuk membuat pelanggan terkonversi memilih produk (CONVERT), variabel perilaku pengguna OFD Grabfood dan Go-food yang berpengaruh adalah Variabel motivasi dengan Pvalue $=0.0015$ | TStatistic $=2.440$ dan kelompok rujukan dengan Pvalue $=0.037 \mid$ TStatistic $=2.094$.

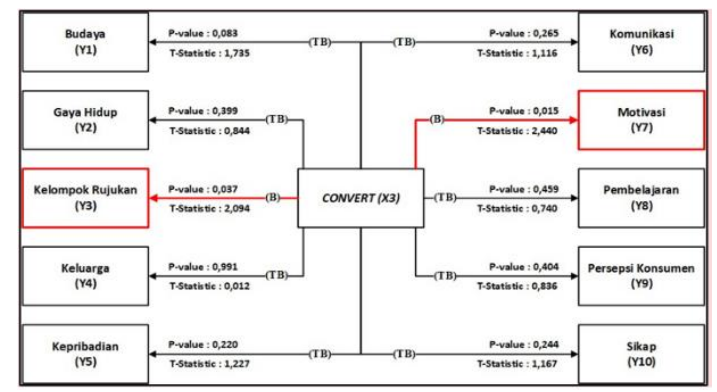

Gambar 8. Hasil Uji Pengaruh antar variabel Perilaku Pengguna pada tahap CONVERT

\section{ENGAGE}

Pada tahap penyusunan Strategi Untuk membuat pelanggan terikat secara emosi terhadap produk dan loyal (ENGAGE), variabel perilaku pengguna OFD Grabfood dan Go-food yang berpengaruh adalah Variabel Budaya, Gaya Hidup, Kelompok Rujukan, Keluarga, Kepribadian, Komunikasi, Pembelajaran, Persepsi Konsumen, Sikap dengan nilai PValue dan TStatistic seperti pada Gambar 8.

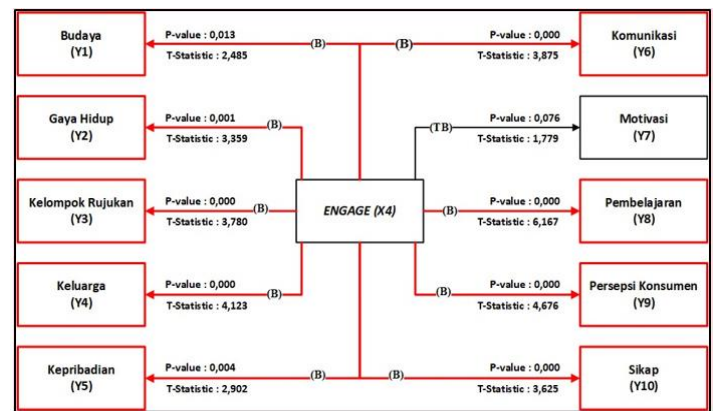

Gambar 8. Tingkat pengaruh antar variabel pada tahap ENGAGE

Selanjutnya dilakukan analisis SEM untuk menentukan Nilai loading Factor. Nilai yang digunakan didalam tahap pembahasan merupakan nilai mean yang berada pada analisis deskriptif dan nilai loading factor yang berada pada uji convergent validity. Kedua nilai ini 
akan menentukan penyusuna strategi digital marketing berdasarkan perilaku pengguna OFD, jika nilai berada pada indikator yang sama berarti nilai dengan angka yang lebih besar lebih diutamakan, sedangkan apabila sebaliknya maka indikator pada loading factor akan diutamakan. Variabel dengan nilai loading factor yang memenuhi kriteria adalah:

\section{REACH}

a. $R E A C H(\mathrm{X} 1) \rightarrow$ Keluarga $(\mathrm{Y} 4)$

ACT
a. $A C T(\mathrm{X} 2) \rightarrow$ Komunikasi (Y6)
b. $A C T(\mathrm{X} 2) \rightarrow$ Persepsi Konsumen (Y9)
c. $A C T(\mathrm{X} 2) \rightarrow$ Sikap (Y10)

\section{CONVERT}

a. CONVERT $(\mathrm{X} 3) \rightarrow$ Kelompok Rujukan

b. CONVERT $(\mathrm{X} 4) \rightarrow$ Motivasi

\section{ENGAGE}

a. $E N G A G E(\mathrm{X} 5) \rightarrow$ Budaya $(\mathrm{Y} 1)$

b. ENGAGE (X5) $\rightarrow$ Gaya Hidup (Y2)

c. ENGAGE (X5) $\rightarrow$ Kelompok Rujukan (Y3)

d. $E N G A G E(\mathrm{X} 5) \rightarrow$ Keluarga (Y4)

e. $E N G A G E(\mathrm{X} 5) \rightarrow$ Kepribadian (Y5)

f. $E N G A G E(\mathrm{X} 5) \rightarrow$ Komunikasi (Y6)

g. $E N G A G E(\mathrm{X} 5) \rightarrow$ Pembelajaran $(\mathrm{Y} 8)$

h. ENGAGE (X5) $\rightarrow$ Persepsi Konsumen (Y9)

i. $E N G A G E(\mathrm{X} 5) \rightarrow$ Sikap (Y10)

Langkah selanjutnya adalah penyusunan Rancangan Strategi Digital Marketing RACE Berdasarkan Perilaku Pelanggan sebagai berikut:

\section{REACH}

Tahap strategi digital marketing REACH menjelaskan tentang bagaimana calon startup agar dapat menjangkau pelanggan sebanyak banyaknya. Variabel yang harus diperhatikan adalah Keluarga. Agar dapat menjangkau pelanggan keluarga dapat dilakukan dengan

:

a. Iklan

Pengambil keputusan didalam keluarga juga menentukan jenis pesan yang berada pada iklan yang akan dibuat. Jika pengambilan keputusan merupakan suami atau istri maka iklan dibuat untuk lebih condong kepada iklan pasangan keluarga yang baru memulai hidup sedangkan apabila pengambilan keputusan berada di tangan anak, maka iklan dibuat dalam bentuk animasi ataupun gambar yang dapat menarik perhatian anak. Contoh Iklan yang menggunakan Keluarga untuk menjadi anchor promosi seperti gambar 9 .

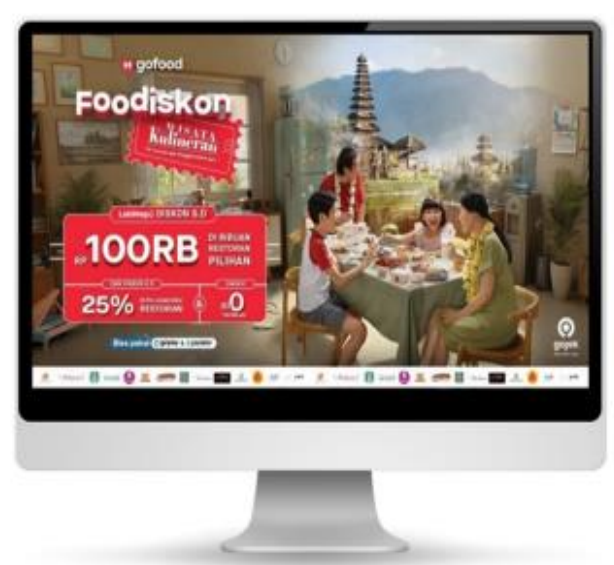

Gambar 9. Strategi Reach - Iklan keluarga

b. Media

Pemilihan media yang dapat menjangkau keluarga adalah hal yang penting. Saat ini, sebagian besar keluarga sudah menggunakan smartphone. Gunakan media yang banyak menjangkau anggota keluarga yaitu Facebook, Instagram, Twitter, maupun Youtube.
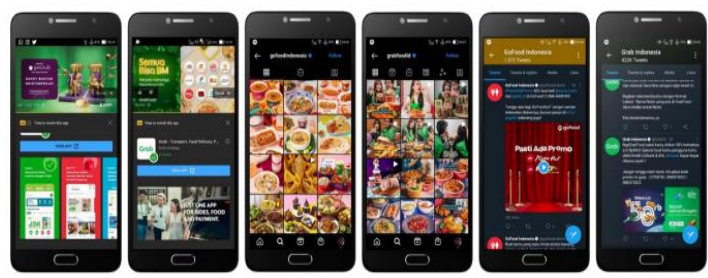

Gambar 10. Strategi Reach - Media Keluarga

c. Kebersihan

Kebersihan adalah hal yang penting bagi keluarga. Yakinkan para anggota keluarga bahwa makanan yang dipesan melalui OFD selalu dalam kondisi kebersihan yang terjaga seperti pada gambar 11 .
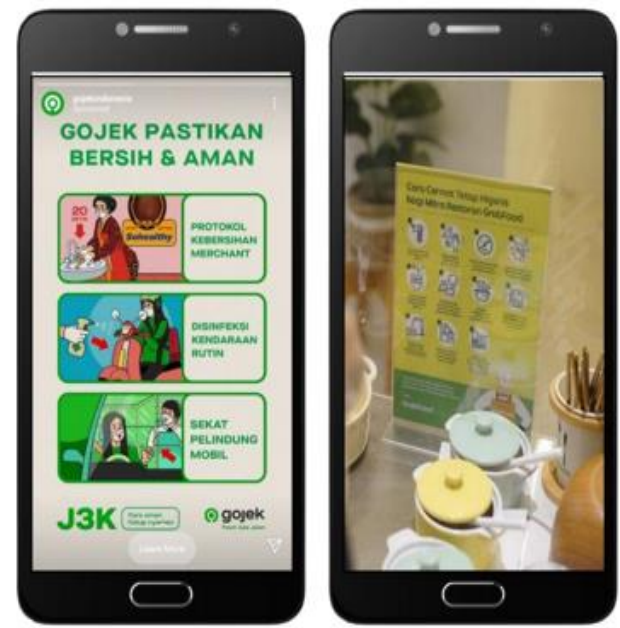

Gambar 11.Strategi Reach - Kebersihan OFD

d. Pengembangan Produk

Pengembangan produk jasa juga harus mementingkan apakah aplikasi yang dikembangkan dapat digunakan dan dimengerti oleh masing-masing 
anggota keluarga, oleh karena itu uji aksesibilitas pada aplikasi juga wajib diperhatikan. Sebagai contoh desain yang dibuat minimalis akan memudahkan para anggota keluarga dalam mencari apa yang mereka inginkan.

\section{e. Penetapan Harga}

Harga yang akan digunakan pada aplikasi wajib memperhatikan harga batasan pada rata-rata keluarga di Indonesia, baik harga makanan maupun harga ongkos kirim makanan tersebut, akan lebih baik apabila harga ongkos kirim tidak melebihi harga dari makanan tersebut.

\section{ACT}

Tahap ACT membahas bagaimana membuat perjalanan pelanggan didalam media digital marketing yang telah kita pilih menjadi menarik.

\section{Komunikasi}

a. Informasi Mudah Ditemukan

Semua informasi layanan OFD dapat dengan mudah ditemukan di search engine, hal ini akan mempermudah para pelanggan dalam mencari informasi mengenai promo atau mengenai fitur layanan terbaru.

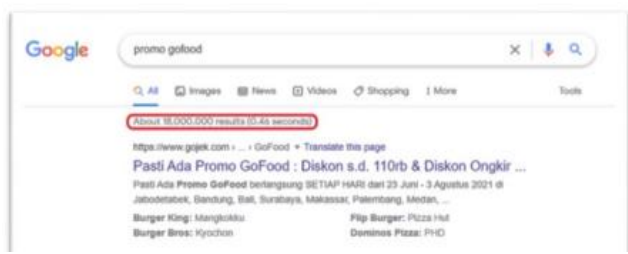

Gambar 12. Strategi ACT - Mudah ditemukan

\section{b. Daya Tarik Desain Aplikasi}

Desain yang dimiliki layanan OFD terlihat minimalis dengan ikon besar yang dapat dilihat dengan mudah oleh para pelanggan. Hal ini dapat mendukung minat pelanggan dalam mencari tahu apa saja fitur yang berada didalam aplikasi.

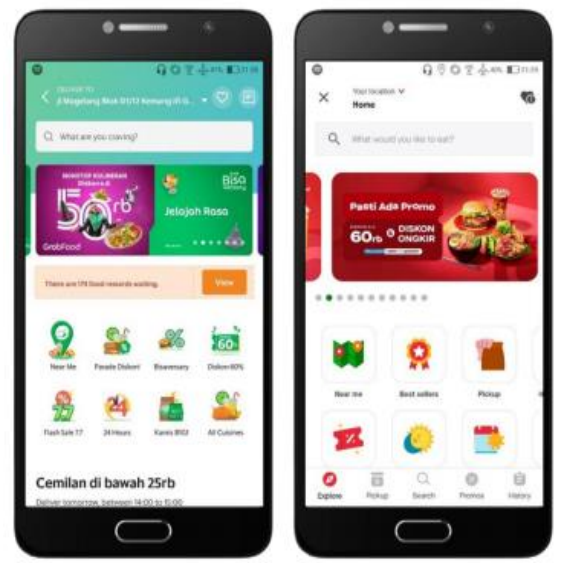

Gambar 13 Strategi ACT - Desain Aplikasi

c. Foto yang Menarik

Semua foto yang telah diposting ke sosial media layanan OFD memiliki representasi yang menarik dan sangat berwana, hal ini dapat menggugah selera makan para pelanggan yang melihatnya, dengan begitu pelanggan akan semakin tergerak untuk melakukan pembelian pada merchant tersebut.
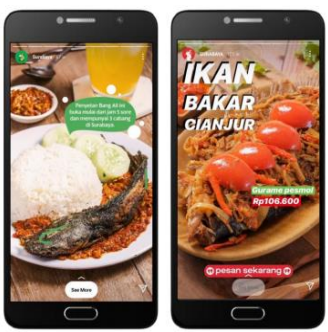

Gambar 14. Strategi $A C T$ - Foto Menarik

d. Integrasi antara Sosial Media

Setiap promo maupun informasi terbaru layanan OFD memiliki integrasi antara sosial media satu dengan lainnya, hal ini berarti apapun sosial media yang digunakan oleh pelanggan, konten kedua layanan ini akan menampilkan informasi yang sama.
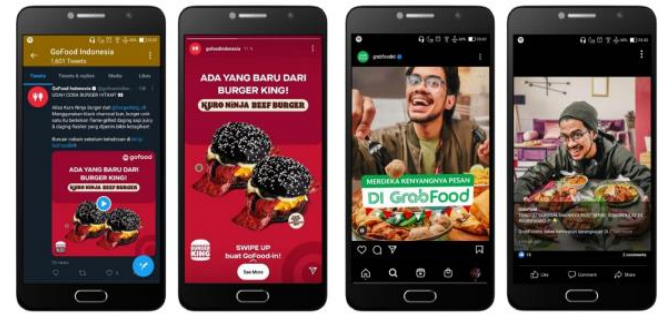

Gambar 15. Strategi $A C T$-Integrasi Sosial Media

\section{Persepsi Konsumen}

Pembentukan persepsi konsumen penting untuk membentuk opini. Buatlah konten menarik agar mendapatkan komentar positif like maupun views dari setiap konten yang di post.
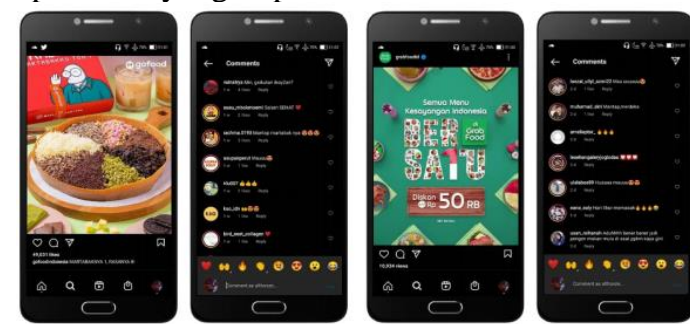

Gambar 16. Strategi $A C T$ - Persepsi Konsumen melalui Konten Yang Menarik

\section{Sikap}

a. Menghemat Waktu

Layanan OFD telah menghemat waktu para pelanggan baik melalui proses pemesanan makanan maupun pada saat makanan diantarkan, hal ini dibuktikan pada kedua layanan OFD terdapat estimasi berapa waktu yang dibutuhkan untuk menyelesaikan pesanan milik pelanggan.

b. Keamanan Jasa Terpecaya

Kedua layanan OFD ini memiliki fitur untuk melacak proses pemesanan makanan, pelanggan dapat melihat posisi driver, keadaan makanan apakah telah selesai disiapkan oleh merchant, maupun identitas driver pengantar makanan semua melalui satu fitur aplikasi. Hal ini akan menimbulkan sebuah sikap percaya kepada jasa 
layanan yang digunakan karena semua aspek dapat terlihat dengan jelas oleh pelanggan.
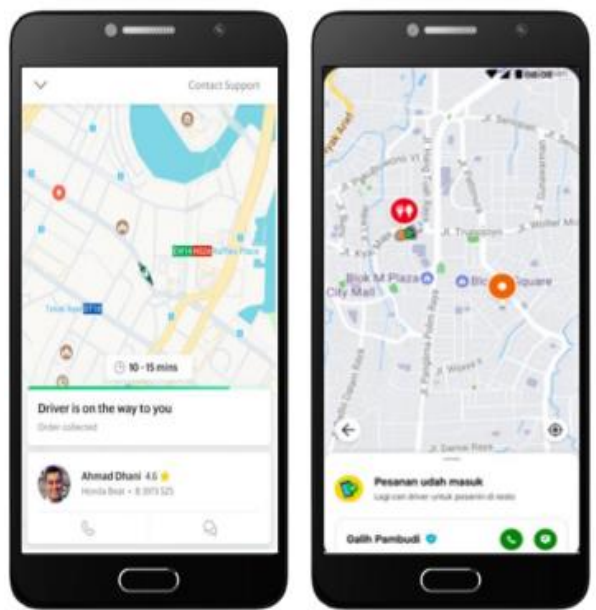

Gambar 17. Strategi ACT - Keamanan

\section{CONVERT}

Tahap CONVERT membahas bagaimana kita merubah pelanggan kita untuk mengambil tahapan pembelian setelah melihat produk/jasa yang kita tawarkan.

\section{Kelompok Rujukan}

a. Promosi Pemesanan Bersama/Porsi Besar

Pemesanan bersama teman /keluarga /Kelompok sangat diminati. Oleh karena buatlah paket /menu /promosi yang memungkinkan pemesanan dilakukan dalam jumlah yang besar.
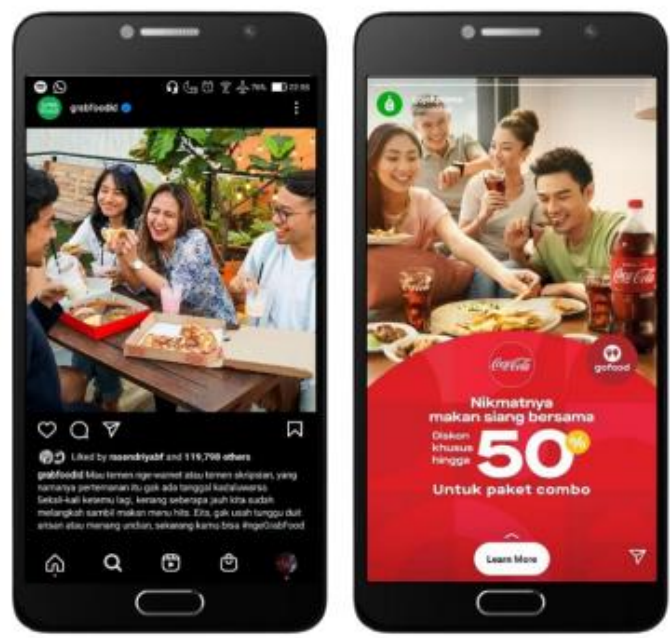

Gambar 18. Strategi Convert - Porsi Besar

b. Penggunaan Para Pakar dalam Iklan Layanan

Manfaatkan pakar beberapa pakar makanan yang cukup populer mulai dari Nex Carlos, Magdalenaf, Ibu Sisca, maupun Dims the Meat Guy. Dengan menggunakan para pakar sebagai tokoh pada iklan para pelanggan akan lebih mempercayai pendapat seseorang yang telah bergelut dibidang makanan dibandingkan dengan orang yang bukan menggeluti bidang makanan.
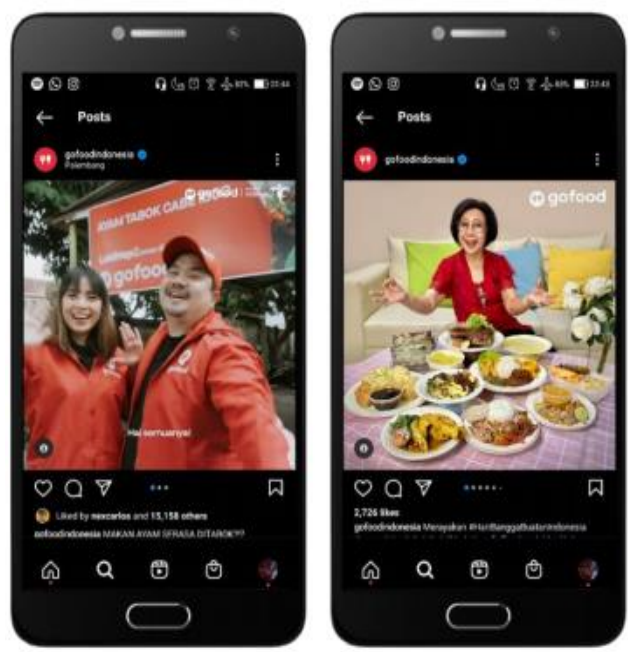

Gambar 19. Strategi Convert - Pakar

\section{Motivasi}

a. Banyak Promo

Promo merupakan potongan harga yang digunakan oleh kedua layanan OFD dalam menarik pelanggan agar dapat menggunakan layanan mereka. Banyak pelanggan tergiur dengan besarnya potongan harga yang diberikan.

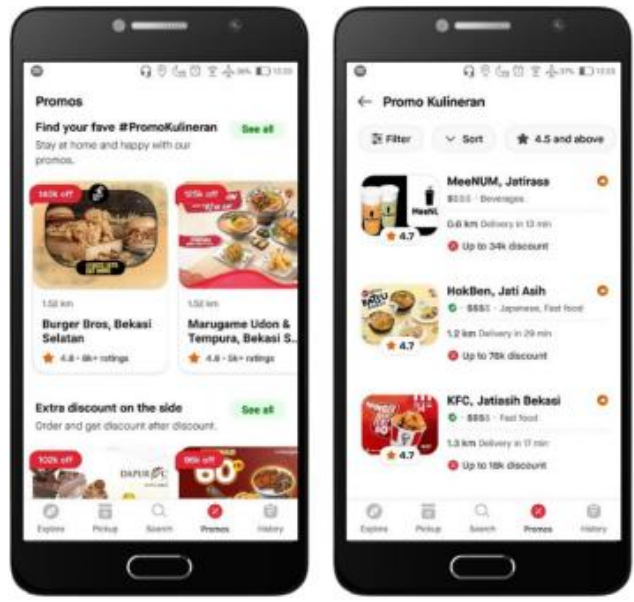

Gambar 20. Strategi Convert Motivasi Promo

b. Tergabung Komunitas Sesama Pengguna

Kedua layanan OFD baik Go-Food maupun GrabFood dapat tergabung dalam suatu komunitas sesama pengguna, yang dimaksud adalah mereka dapat bertukar informasi mengenai berbagai merchant rekomendasi, masalah aplikasi, maupun tips $\&$ trik dalam melakukan pemesanan atau menggunakan promo. Sedangkan para pelanggan yang telah menggunakan layanan ini dapat terhidar dari berbagai macam penghinaan karena tidak menggunakan layanan OFD. 

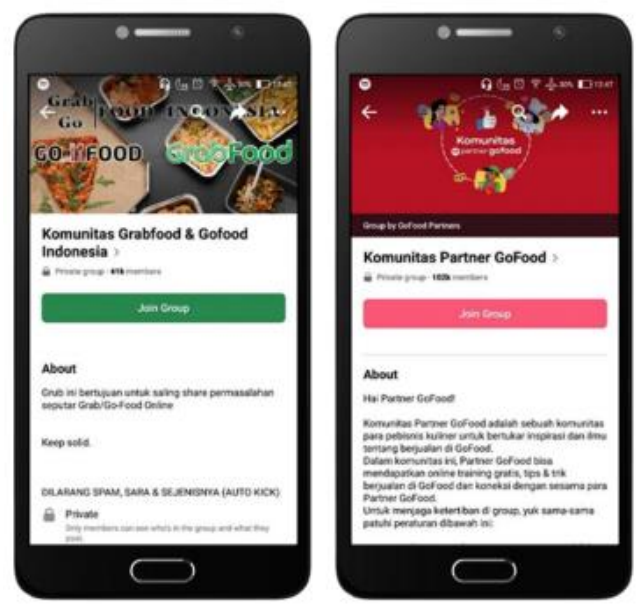

Gambar 20. Strategi Convert Komunitas

\section{ENGAGE}

Tahap ENGAGE membahas bagaimana kita akan membangun hubungan dengan pelanggan agar terciptanya sebuah loyalitas pelanggan. Oleh sebab itu perhatikan beberapa parameter berikut untuk membangun Engagement.

\section{Budaya}

Pada hari-hari besar kebudayaan seperti Hari Raya Imlek ataupun Hari Raya Idul Fitri kedua layanan ini membuat beberapa konten ucapan dan promo berupa voucher untuk menarik para pelanggan, selain itu dengan melakukan ucapan ini pelanggan akan merasa lebih dihargai oleh perusahaan dan kedepannya akan menimbulkan sebuah rasa loyalitas.
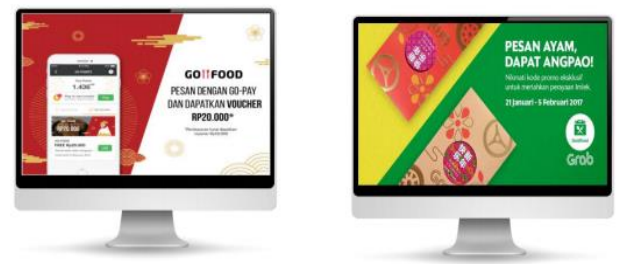

Gambar 22. Strategi Engage - Budaya

\section{Gaya Hidup}

Gaya Hidup Generasi Z menyukai hal yang praktis. Salah satu bentuk kepraktisan adalah Kemudahan pembayaran. Upayakan agar menerima pembayaran secara tunai maupun epayment. Lakukan kerjasama dengan berbagai pihak. Dengan adanya kerja sama dengan beberapa perusahaan pelanggan dapat memilih metode pembayaran mana yang sesuai dengan gaya hidup pelanggan.

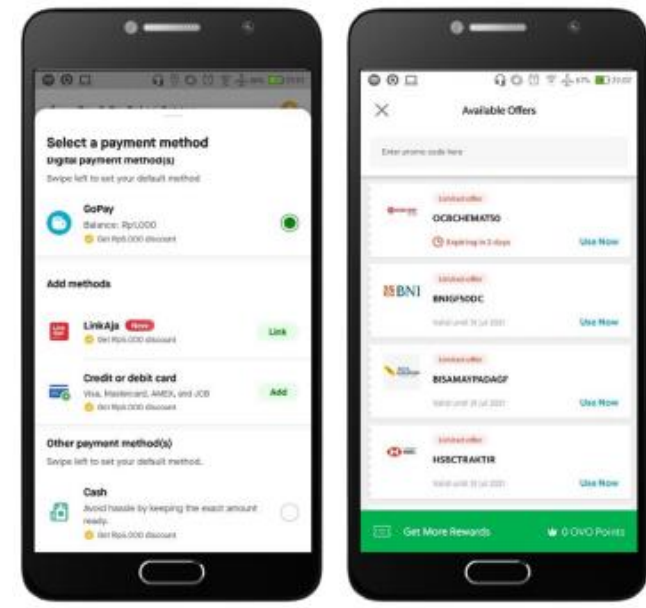

Gambar 23 Strategi Engage Gaya Hidup

\section{Kelompok Rujukan}

Kelompok rujukan menyukai aktivitas yang dilakukan secara bersama sama. Buatlah fitur yang memungkinkan mereka melakukan hal ini. Contoh Order Bersama merupakan salah satu fitur layanan OFD Go-Food yang dapat melakukan pemesanan dari berbagai macam merchant dalam satu lokasi yang sama (mall,foodcourt, dapur go-food) dengan satu tarif ongkos kirim yang sama.

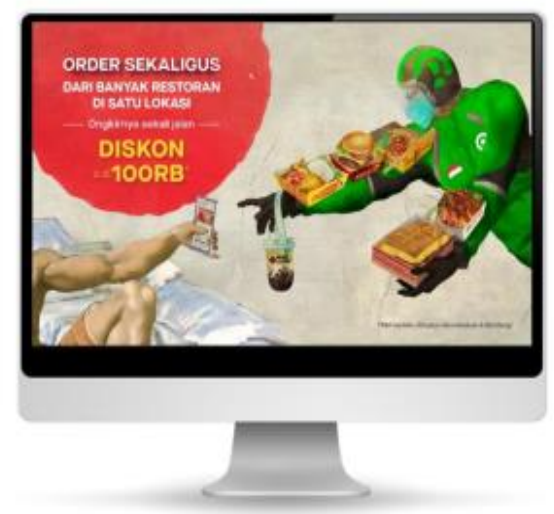

Gambar 24. Strategi Engage Kelompok Rujukan

\section{Keluarga}

Buatlah promo yang bertemakan keluarga secara rutin, seperti "sekeluarga makan meriah di rumah aja". Buatlah berbagai macam resep yang dapat dibuat dirumah, hal ini akan menimbulkan pengalaman yang baik bagi para keluarga karena mereka tidak hanya melakukan pemesanan makanan tetapi juga mendapatkan informasi mengenai resep-resep yang dapat dibuat dirumah. 

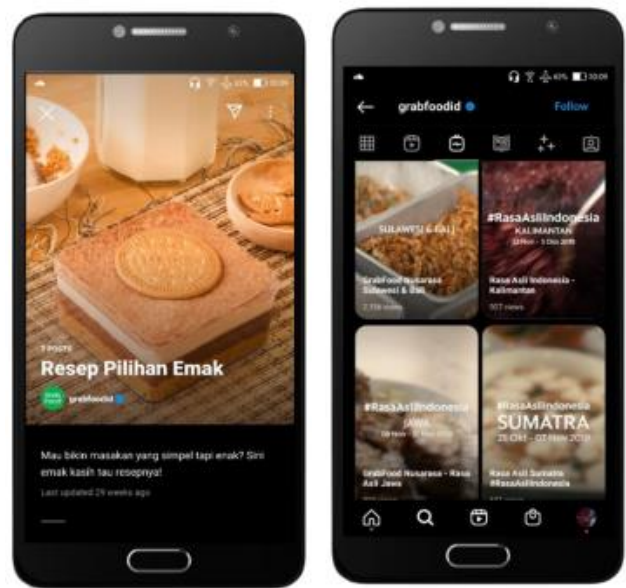

Gambar 25. Strategi Engage Keluarga

\section{Kepribadian}

Generasi Z memiliki kepribadian yang menyukai visual dan verbal. Gunakan iklan yang mencakup verbal dan visual agar para pelanggan dapat lebih mudah mencerna apa arti dari kata-kata didalam iklan tersebut.
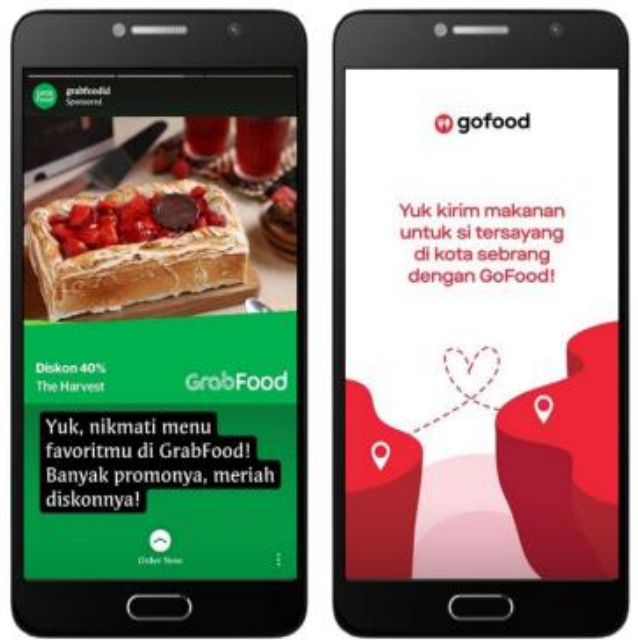

Gambar 26. Strategi Engage Kepribadian

\section{Komunikasi}

Generasi Z menyukai Kata-Kata berbentuk Pesan Personal. Bangunlah komnikasi dengan mereka melalui berbagai bentuk pesan personal. Hal ini akan membuat pelanggan merasa lebih diperhatikan dibandingkan dengan kata-kata yang ditujukan untuk kelompok.

\section{Pembelajaran}

Pengalaman baik maupun buruk tidak hanya terjadi karena aplikasi tidak baik atau layanan yang buruk, hal ini bisa terjadi dikarenakan kurang terlatihnya merchant makanan maupun driver pengantar layanan makanan. Oleh karena itu kedua layanan ini bekerjasama dengan para pakar industri kuliner untuk mengembangkan pelatihan yang mencakup managemen operasional, branding \& marketing, pengembangan produk sampai dengan permodalan.

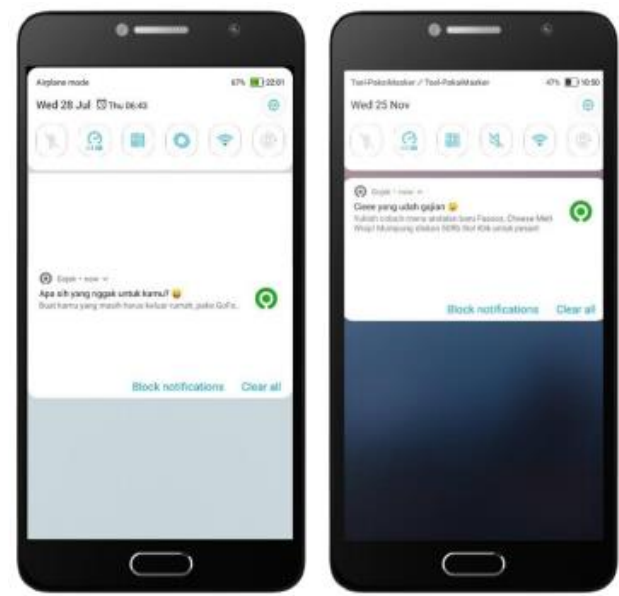

Gambar 27. Strategi Engage Komunikasi
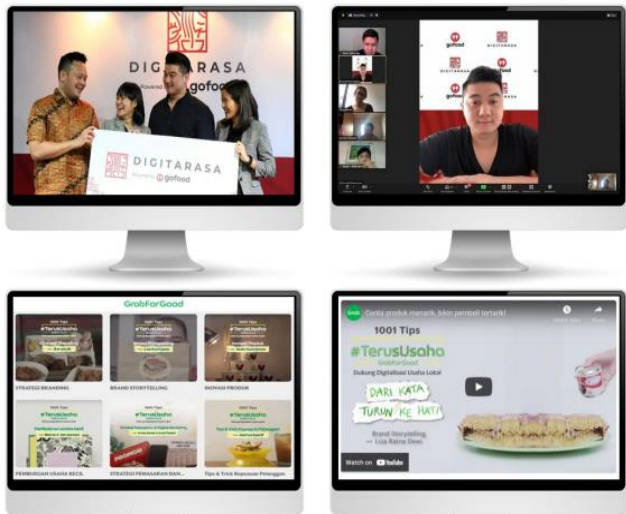

Gambar 28. Strategi Engage Pembelajaran

Selain itu pembelajaran juga bisa dilakukan dengan memberi materi tata cara petunjuk bagaimana proses pemesanan makanan lengkap dengan tahapan dan gambar.
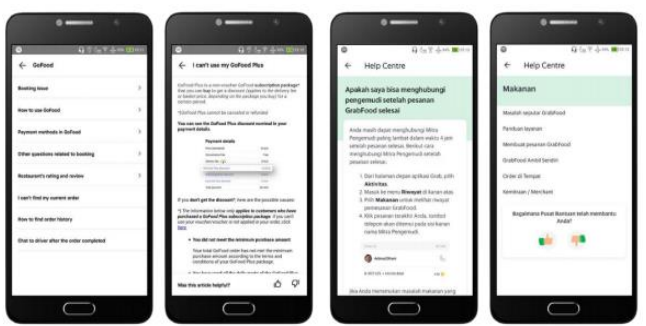

Gambar 29. Strategi Engage Petunjuk

\section{Persepsi Konsumen}

Strategi untuk mengikat konsumen adalah dengan menciptakan persepsi konsumen. Kecepatan pengiriman memiliki pengaruh cukup besar pada persepsi konsumen, semakin cepat sebuah pesanan pelanggan datang maka semakin besar tingkat kepuasaan yang diberikan oleh pelanggan kepada layanan, Agar pelanggan tidak kecewa akibat proses pesanan cukup lama kedua layanan menampilkan proses estimasi pemesanan sampai ketempat tujuan. 


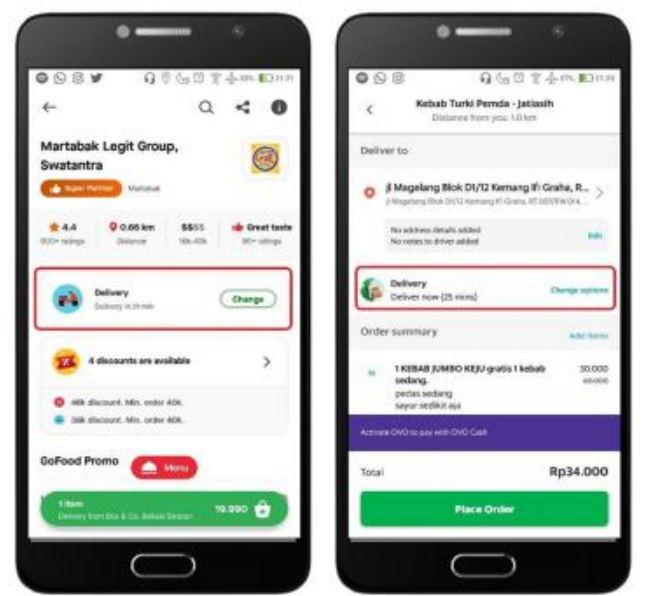

Gambar 30. Strategi Engage Persepsi Konsumen

\section{Sikap}

Sikap menyukai menyukai perlu dibangun karena dapat menyebabkan pelanggan melakukan pembelian secara berulang kali atau bahkan menyarankan layanan kepada orang lain, dan sebaliknya apabila pelanggan tidak menyukai layanan ini maka dapat menyebabkan pelanggan menceritakan ketidaksukaan terhadap orang lain. Untuk mengantisipasi hal-hal yang tidak disukai oleh pelanggan kedua layanan OFD selalu terbuka terhadap setiap masalah yang dihadapi oleh pelanggan.
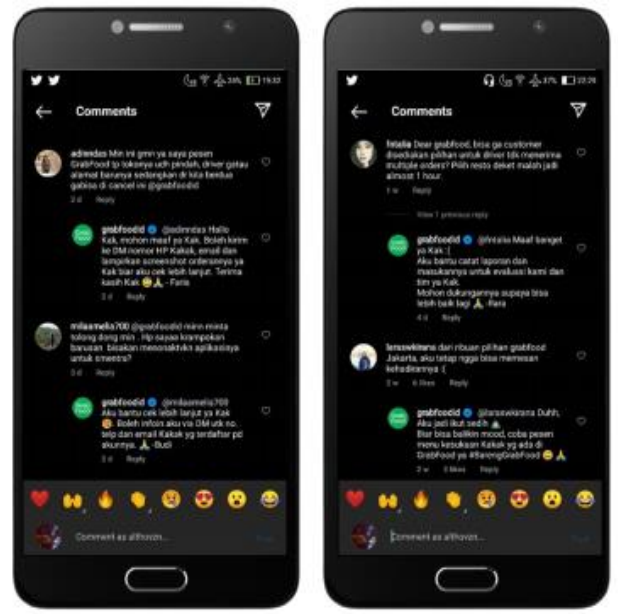

Gambar 31 Strategi Engage Sikap

\section{KESIMPULAN}

Berdasarkan hasil perhitungan dan analisis perancangan strategi Digital Marketing dengan metode RACE pada layanan Online Food Delivery berdasarkan Perilaku Pelanggan Generasi Z dengan studi kasus pada Go-Food dan GrabFood Surabaya didapatkan kesimpulan bahwa untuk membangun merek suatu produk/jasa maka faktor keluarga seperti siapa pengambil keputusan dalam setiap pembelian produk/jasa dalam keluarga tersebut dan media apa yang sering digunakan dalam keluarga tersebut merupakan hal yang paling penting, hal ini didukung oleh hasil nilai Tstatistik sebesar 2,557. Dalam tahap membangun interaksi dengan pelanggan faktor komunikasi yang meliputi informasi mudah dijangkau, desain aplikasi dan content yang menarik, serta dapat terintegrasi dengan beberapa media sosial merupakan faktor yang sangat penting, hal ini didukung oleh hasil nilai T-statistik sebesar 4,657,

Disamping itu, untuk mengubah interaksi menjadi suatu pembelian maka faktor motivasi dengan menghadirkan banyak promo dan tergabung dalam komunitas sesama pengguna menjadi hal yang sangat penting dan menempati posisi T-statistik terbesar yakni 2,44 , sedangkan untuk meningkatkan hubungan dengan pelanggan pada dasarnya sebagian besar indikator dalam perilaku pelanggan berkontribusi positif, namun faktor persepsi konsumen yang meliputi kecepatan pengiriman dan respon pelanggan menjadi faktor utama dengan nilai T-statistik 4,676.

\section{SARAN}

Adapun saran untuk penelitian selanjutnya yaitu responden tidak hanya berasal dari kota Surabaya saja, tetapi dapat dikembangkan ke kota besar lain yang ada di Indonesia, selain itu juga dapat menambahkan analisis pada perilaku pelanggan pada generasi $\mathrm{X}$ maupun $\mathrm{Y}$ yang tersebar di seluruh Indonesia.

\section{DAFTAR PUSTAKA}

[1] CNBC Indonesia. (2019, Oktober 7). Alasan Gojek \& Grab Genjot Bisnis GoFood dan GrabFood. Dipetik April 8, 2020, dari https://www.cnbcindonesia.com/tech/2019100714 1721-37-104960/alasan-gojek-grab-genjot-bisnisgofood-dan-grabfood

[2] Marketeers. (2018, Januari 13). Meraba Masa Depan Layanan Food Delivery Startup di Indonesia. Dipetik April 16, 2020, dari Marketeers: https://marketeers.com/meraba-masa-depanlayanan-food-delivery-startup-di-indonesia/

[3] Badan Ekonomi Kreatif. (2018). Mapping \& Database Startup Indonesia 2018. Indonesia: MIKTI dan Teknopreneur Indonesia. Dipetik April 10,2020

[4] Suryani, T. (2013). Perilaku Konsumen di Era Internet (1 ed.). Yogyakarta: Graha Ilmu.

[5] Setiawan, F. T., Suharjo, B., \& Syamsun, M. (2018, September). Strategi Pemasaran Online UMKM Makanan (Studi Kasus di Kecamatan Cibinong). Manajemen IKM, 13, 116-126. Dipetik April 22, 2020,

dari https://journal.ipb.ac.id/index.php/jurnalmpi/articl e/view/24546/130203

[6] Teixeira, S., Branco, F., Oliveira, M., Moreira, F., Goncalves, R., Cota, M., \& Jorge, F. (2018). Main Factors in the Adoption of Digital Marketing in Startups. INESCTEC. Dipetik Februari 14, 2020, dari

http://repositorio.inesctec.pt/handle/123456789/96 15

[7] Bisri, M. H. (2018). Perancangan Strategi Digital Marketing Dengan Metode Sostac Pada Stratup 
Qtaaruf. Diambil kembali dari Repository Dinamika: https://repository.dinamika.ac.id/id/eprint/3285/

[8] Agnes, J. (2016). Perancangan Strategi Online Marketing Berbasis Media Sosial Pada Perusahaan Eiden. Jurnal Peforma, 1. Diambil kembali dari https://journal.uc.ac.id/index.php/performa/article/ view/342

[9] SmartInsight. (2018). RACE Planning Framework. Dipetik April 19, 2020, dari Smart Insights: https://www.smartinsights.com/tag/race-planningsystem/

[10] IDN Times. (2019, Februari 19). Millennials Kecanduan Pesan Antar Makanan, Hemat Waktu atau Malas? (P. Cahya, Produser) Dipetik Mei 19, 2020, dari IDN Times: https://www.idntimes.com/food/diningguide/putriana-cahya/millennials-kecanduanpesan-antar-makanan-hemat-waktu-atau-malas/7 